NASA Technical Memorandum 106363

AIAA-94-0687

\title{
Cryogenic Spray Vaporization in High-Velocity Helium, Argon and Nitrogen Gasflows
}

Robert D. Ingebo

Lewis Research Center

Cleveland, Ohio

Prepared for the

AIAA 32nd Aerospace Sciences Meeting and Exhibit

sponsored by the American Institute of Aeronautics and Astronautics

Reno, Nevada, January 10-13, 1994 


\title{
CRYOGENIC SPRAY VAPORIZATION IN HIGH-VELOCITY HELIUM, ARGON
}

\section{AND NITROGEN GASFLOWS}

\author{
Robert D. Ingebo \\ National Aeronautics and Space Administration \\ Lewis Research Center \\ Cleveland, Ohio 44135
}

\section{Abstract}

Effects of gas properties on cryogenic liquid-jet atomization in high-velocity helium, nitrogen and argon gasflows were investigated. Volume median diameter, $\mathrm{D}_{\mathrm{v} .5 \mathrm{e}}$, data were obtained with a scattered-light scanning instrument. By calculating the change in spray dropsize, $-\Delta \mathrm{D}_{\mathrm{v} .5}^{2}$, due to droplet vaporization, it was possible to calculate $D_{v .5 c}$ from the expression, $-\Delta D_{v .5}^{2}$ $=\mathrm{D}_{\mathrm{v} .5 \mathrm{e}}^{2}-\mathrm{D}_{\mathrm{v} .5 \mathrm{c}}^{2} \cdot \mathrm{D}_{\mathrm{v} .5 \mathrm{c}}^{2}$ is the unvaporized characteristic dropsize formed at the fuel-nozzle orifice. $\mathrm{D}_{\mathrm{v} .5 \mathrm{c}}^{2}$ was normalized with respect to liquid-jet diameter, $\mathrm{D}_{\mathrm{o}}$, to give the dimensionless ratio $\mathrm{D}_{\mathrm{o}} / \mathrm{D}_{\mathrm{v} .5 \mathrm{c}}^{2}$. It was then correlated with several dimensionless groups to give the following expression:

$$
\frac{\mathrm{D}_{\mathrm{o}}}{\mathrm{D}_{\mathrm{v} .5 \mathrm{c}}}=\mathrm{k}_{\mathrm{c}}\left(\mathrm{WeRe} \frac{\rho_{\mathrm{g}}}{\rho_{\mathrm{l}}}\right)^{0.44}\left[\left(\frac{\rho_{\mathrm{l}} \mathrm{V}_{\mathrm{m}}^{3}}{\mathrm{~g} \mu_{\mathrm{g}}}\right)\left(\frac{\mathrm{T}_{\mathrm{g}}}{\mathrm{T}_{\mathrm{o}}}\right)\right]^{0.75}
$$

where $k_{c}$ is a proportionality constant, WeRe is the product of Weber and Reynolds number, $\rho_{g} / \rho_{\ell}$ is the fluid density ratio, and $\rho_{\ell} \mathrm{V}_{\mathrm{m}}^{3} / \mathrm{g} \mu_{\mathrm{g}}$ is a molecular-scale group derived in this study to correlate the original characteristic dropsize, $\mathrm{D}_{\mathrm{v} .5 \mathrm{c}}$, with atomizing forces produced by the three atomizing gases. This expression, for the volume median diameter of cryogenic $\mathrm{LN}_{2}$ sprays, correlates dropsize $\mathrm{D}_{\mathrm{v} .5 \mathrm{c}}$ with aerodynamic and liquidsurface forces so that it can be readily determined in the design of multiphase-flow propellant injectors for rocket combustors.

\section{Nomenclature}

A fuel nozzle orifice area, $\mathrm{cm}^{2}$

a acceleration, $\mathrm{cm} / \mathrm{sec}^{2}$

$\mathrm{C}_{\mathrm{d}}$ drag coefficient

$\mathrm{D}_{\mathrm{o}} \quad$ liquid-jet diameter, $\mathrm{cm}$

$\mathrm{D}_{\mathrm{v} .5}$ volume median drop diameter, $\mathrm{cm}$

k correlation coefficient for Eq. (1)

$\mathrm{k}^{\prime} \quad$ correlation coefficient for Eq. (7)

$\mathrm{k}^{\prime \prime} \quad$ correlation coefficient for Eq. (12)
Nu heat-transfer Nusselt number, based on $D_{v .5 e}$

n exponent for Eq. (1)

Re Reynolds number based on $D_{v .5 e}$

$T_{\text {。 }}$ ambient airflow temperature, $293 \mathrm{~K}$

t vaporization time, sec

$\mathrm{V}_{\mathrm{c}}$ acoustic velocity, $\mathrm{cm} / \mathrm{sec}$

W weight flow of fluid, $\mathrm{g} / \mathrm{sec}$

We Weber number based on $\mathrm{D}_{\mathrm{v} .5 \mathrm{e}}$

$\mathbf{x}$ axial downstream spray sampling distance

$\mu \quad$ absolute viscosity, $\mathrm{g} / \mathrm{cm}$ sec

$\rho$ fluid density, $\mathrm{g} / \mathrm{cm}^{3}$

$\sigma \quad$ surface tension relative to air, dyne $/ \mathrm{cm}$

Subscripts

c calculated

d droplet

e experimental

f film

g gaseous nitrogen, $\mathrm{GN}_{2}$

e liquid nitrogen, $\mathrm{LN}_{2}$

- orifice

\section{Introduction}

The performance of liquid-fuel atomizers in gas turbine and rocket engines can be markedly improved when fuel-spray surface areas are increased. This will give a corresponding increase in droplet vaporization and burning rates. Previous water spray studies reported in Ref. 1 have shown that two-fluid fuel nozzles can produce large numbers of very small drops, i.e., sprays with large surface-area-to-volume ratios. Small fuel droplets produced with this type of atomizer, vaporize rapidly so that it can even be used to form premixed-prevaporized fuel-air mixtures suitable for catalytic combustors. In the case of rocket combustors, the two-fluid propellant nozzle is used quite extensively, i.e., in the main engines of the space shuttle. 
In studying sprays produced with two-fluid fuel nozzles, Ref. 1, dropsize measurements were made close to the fuel-nozzle orifice to avoid the loss of very small water droplets due to vaporization. However, in the present study of highly volatile liquid-jet breakup, it was necessary to determine effects of droplet vaporization and acceleration on dropsize measurements, in order to calculate original unvaporized spray dropsize and compare it with that predicted by atomization theory. This is due to the fact that $\mathrm{LN}_{2}$ jets injected into highvelocity gasflow will quickly breakup into large numbers of very small drops, i.e., in the order of 1 to $10 \mu \mathrm{m}$. Some of the very small drops vaporized completely before passing through the laser beam, which was located at a distance of $1.2 \mathrm{~cm}$ downstream of the fuel nozzle orifice. As a result, only measurements of partially vaporized sprays could be obtained experimentally. In order to compare results of this study with atomization theory, the initially unvaporized value of $D_{v .5 c}$ was determined by means of the following expression: $D_{\mathrm{v} .5 \mathrm{c}}^{2}$ $=\mathrm{D}_{\mathrm{v} .5 \mathrm{e}}^{2}-\Delta \mathrm{D}_{\mathrm{v} .5}^{2}$. Droplet vaporization and acceleration rates were calculated by using heat-transfer and drag coefficient expressions derived in Ref. 2. Values of $\Delta D_{\mathrm{v} .5 \mathrm{c}}^{2}$ could then be calculated and used to determine original values of $D_{v .5 c}$ that existed before vaporization had occurred.

Cryogenic sprays with relatively large surface-areas per unit volume are desirable since they produce rapid fuel spray vaporization and efficient combustion in rocket combustors. In order to calculate increases in the efficiency of a fuel spray combustion process, vaporization and burning rate expressions are needed to compute changes in the surface-area of a vaporizing fuel spray. Such mathematical expressions were investigated in the present study of $\mathrm{LN}_{2}$ jets breaking up in $\mathrm{He}, \mathrm{N}_{2}$ and $\mathrm{Ar}$ gasflows. This information is needed to develop fuelspray combustion models. Also, wide ranges of liquid fuel and atomizing-gas properties need to be investigated, so that fuel-spray combustion models can be directly applied to develop more efficient fuel atomizers, improve combustor performance and reduce exhaust emissions.

In the present investigation of vaporizing $\mathrm{LN}_{2}$ sprays, measurement of $\mathrm{D}_{\mathrm{v} .5 \mathrm{e}}$ were made in the presence of relatively high thermal gradients. The atomizing gases, i.e., $\mathrm{He}, \mathrm{N}_{2}$ and $\mathrm{Ar}$, were at room temperature, $293 \mathrm{~K}$, whereas $\mathrm{LN}_{2}$ droplet surface temperatures were near the boiling point of $\mathrm{LN}_{2}, 77 \mathrm{~K}$. As a result, heat transfer across the gas-film had a driving potential $\Delta \mathrm{T}$, of $216 \mathrm{~K}$. This is considerably higher than that encountered in the study of water sprays, as discussed in Ref. 1. In that study, the effect of vaporization on dropsize measurements of water sprays was negligible, when measurements were made very close to the fuel nozzle orifice. However, in the present study of $\mathrm{LN}_{2}$ sprays, the droplets vaporized quite rapidly.

The effects of atomizing-gas mass flux and gas velocity on spray dropsize have been studied by numerous investigators as reported in Refs. 1-7. Atomization theory predicts that the characteristic dropsize, $D_{c}$, is proportional to $\mathrm{V}_{\mathrm{g}}^{\mathrm{n}}$, where $\mathrm{n}=-1.33$. However, as shown in Table I, exponents determined by various investigators varied from -1.00 to -1.33 . This disagreement can be attributed to the effect of droplet vaporization on dropsize measurements, when they were taken relatively far downstream of the atomizer orifice. This was shown to be true for water sprays, as reported in Ref. 1, when sampling distance downstream of the atomizer was increased from 2.2 to $6.7 \mathrm{~cm}$. As a result, the exponent for $\mathrm{V}_{\mathrm{g}}$ decreased from -1.33 to -1.00 .

To determine effects of atomizing-gas properties on $\mathrm{LN}_{2}$ jet breakup in high-velocity gasflows of $\mathrm{He}, \mathrm{N}_{2}$ and $\mathrm{Ar}$, the characteristic dropsize $\mathrm{D}_{\mathrm{v} .5}$ of the cryogenic sprays was measured with a scattered-light scanner developed at NASA Lewis Research Center by Buchele, Ref. $8 . \mathrm{LN}_{2}$ sprays were sampled at a distance of $1.2 \mathrm{~cm}$ downstream of the fuel nozzle to minimize losses of very small droplets due to vaporization. Values of $D_{v .5 e}$ varied from 3 to $30 \mu \mathrm{m}$ and measurements were made at an atomizing-gas temperature of $293 \mathrm{~K}$.

\section{Apparatus and Procedure}

In a two-fluid fuel nozzle, helium, nitrogen and argon gasflows were used to breakup liquid-nitrogen, $\mathrm{LN}_{2}$, jets as shown in Fig. 1. The atomizer was mounted at the center line of the $24-\mathrm{cm}$ diameter duct and operated over $\mathrm{LN}_{2}$ and atomizing-gas pressure ranges of 0.2 to $1.0 \mathrm{MPa}$.

$\mathrm{LN}_{2}$ sprays were injected downstream into the airflow, just upstream of the duct exit, and sampled at a distance of $1.2 \mathrm{~cm}$ downstream from the atomizer orifice to the center line of the $4.4-$ by $1.9-\mathrm{cm}$ laser beam. The two-fluid nozzle was fabricated according to the diagram illustrated in Fig. 2. $\mathrm{LN}_{2}$ at a temperature of $77 \mathrm{~K}$ was axially injected into the airstream by gradually opening the control valve until the desired flowrate of $51 \mathrm{~g} / \mathrm{sec}$ was obtained as indicated by a turbine flowmeter. The atomizing gas was then turned on and weight flowrate was measured with a $0.51-\mathrm{cm}$ diameter sharp-edge orifice. After atomizing gas and $\mathrm{LN}_{2}$ flowrates were set, the volume median diameter, $\mathrm{D}_{\mathrm{v} .5 \mathrm{e}}$, was measured with the scattered-light scanner.

The optical system of the scattered-light scanner shown in Fig. 3 consisted of a laser beam expander with spatial filter, rotating scanning-slit and a detector. The 
instrument measures scattered light as a function of scattering angle by repeatedly sweeping a variablelength slit in the focal plane of the collecting lens. The data obtained is scattered-light energy as a function of the scattering angle relative to the laser beam axis. This method of particle size measurement is similar to that described in Ref. 9. According to Buchele, ${ }^{8}$ measurements of scattered-light energy normalized by the maximum energy and plotted against scattering angle can be used to determine the volume median diameter, $\mathrm{D}_{\mathrm{v} .5 \mathrm{e}}$. Also, this method of determining characteristic dropsize and dispersion of dropsize can be used independent of particle size distribution function, according to Buchele. ${ }^{8}$ For a typical measurement, the scan is repeated 60 times per second to average out any temporal variations in the energy curve.

Spray pattern effects were minimized by measuring $\mathrm{D}_{\mathrm{v} .5 \mathrm{e}}$ for the entire cloud of droplets. The instrument was calibrated with five sets of monosized polystyrene spheres having diameters of $8,12,25,50$ and $100 \mu \mathrm{m}$. Since the sprays were sampled very close to the atomizer orifice, they contained a relatively high number-density of very small droplets. As a result, the light-scattering measurements required correction for multiple scattering as described in Ref. 10. Also, dropsize measurements were corrected to include Mie scattering theory when very small drop diameters, i.e., $10 \mu \mathrm{m}$, were measured. Reproducibility tests showed that experimental measurements agreed within \pm 5 percent. Background effects due to severe gas-density gradients were negligible due to taking background readings with a high-temperature atomizing gas flowing through the nozzle and thereby obtaining corrected light-scattering curves for measuring the spray dropsize.

\section{Experimental Results}

Measurements of the volume median diameter were obtained by sampling the entire $\mathrm{LN}_{2}$ spray cross section with the laser beam center line located at a distance of $1.2 \mathrm{~cm}$ downstream of the fuel nozzle orifice, as shown in Fig. 3. Partially vaporized droplets traveled a distance of $2.0 \mathrm{~cm}$ through the scattered-light scanner laser beam. However, some of the very small droplets were completely vaporized before they could exit the laser beam. As a result, measurements of $\mathrm{D}_{\mathrm{v} .5 \mathrm{e}}$ were obtained for partially vaporized $\mathrm{LN}_{2}$ sprays. Thus, it was necessary to calculate the change in dropsize, $\Delta \mathrm{D}_{\mathrm{v} .5}^{2}$, in order to determine the initially unvaporized spray dropsize, $\mathrm{D}_{\mathrm{v} .5 \mathrm{c}}$, that was formed at the fuel-nozzle orifice.

\section{$\underline{\text { Variation of } \mathrm{D}_{\mathrm{v}} .5 \mathrm{e} \text { With Atomizing-Gas Flowrate }}$}

Experimental values of $\mathrm{D}_{\mathrm{v} .5 \mathrm{e}}$ obtained with the scattered-light scanner are plotted against atomizing- gas flowrate, $\mathrm{W}_{\mathrm{g}}$, as shown in Fig. 4. High-velocity gasflows were used and $\mathrm{LN}_{2}$ jet breakup occurred primarily in the regime of aerodynamic stripping. No indication of secondary breakup of droplets was observed, since the low gas-velocity regime of capillary wave breakup of liquid jets was not investigated. From the plot shown in Fig. 4, the following expression was obtained for reciprocal $\mathrm{D}_{\mathrm{v} .5 \mathrm{e}}$ :

$$
D_{v .5 e}^{-1}=k_{e} W_{g}^{n}
$$

Values of the proportionality constant $\mathrm{k}_{\mathrm{e}}$ and exponent $\mathrm{n}$ are given in Table II, for the three atomizing gases helium, nitrogen and argon, respectively. The following expression was obtained for nitrogen gasflow: $D_{v}^{-1} \cdot 5 e$ $=275 \mathrm{~W}_{\mathrm{n}}^{1.11}$, where values of $\mathrm{D}_{\mathrm{v} .5 \mathrm{e}}^{-1}$ and $\mathrm{W}_{\mathrm{n}}$ are expressed as $\mathrm{cm}^{-1}$ and $\mathrm{g} / \mathrm{sec}$, respectively.

The value of $\mathrm{n}=1.11$ is considerably less than that of $\mathbf{1 . 3 3}$ predicted by atomization theory, for liquidjet breakup in high-velocity gasflow. This discrepancy is attributed to the loss of very small vaporizing $\mathrm{LN}_{2}$ drops, before dropsize measurements could be completed with the scattered-light scanner. In the present study, results agree better with theory than those reported in Ref. 11, since an allowance is made for the effect of droplet vaporization on dropsize measurements of highly volatile sprays. This effect was not accounted for in Ref. 11 and although the dropsize data did appear to agree with theory, the proportionality constant $\mathrm{k}$ was too low to adequately characterize an initially unvaporized spray. As a result, the study in Ref. 11 did not take into account the fact that very small drops could be completely vaporized before passing through the laser beam.

\section{Droplet Acceleration}

Effects of droplet vaporization rate on experimental values of $D_{v .5 e}$ were determined by calculating vaporization time, $t$, as based on the velocity $V_{d}$ for characteristic dropsize $\mathrm{D}_{\mathrm{v} .5 \mathrm{e}}$. Time, $\mathrm{t}$, was calculated for a distance of $2.2 \mathrm{~cm}$, i.e., from nozzle orifice to downstream edge of laser beam, as shown in Fig. 3.

Volume median drop velocity, $\mathrm{V}_{\mathrm{d}}$ and acceleration, $a$, of liquid nitrogen droplets were calculated using the following momentum balance, as given in Ref. 8:

$$
\mathrm{m}_{\mathrm{d}^{\mathrm{a}}}=\frac{1}{2} \rho_{\mathrm{g}} \mathrm{A}_{\mathrm{d}}\left(\mathrm{V}_{\mathrm{g}}-\mathrm{V}_{\mathrm{d}}\right)^{2} \mathrm{C}_{\mathrm{d}}
$$

where $m_{d}$ and $A_{d}$ are mass and area of dropsize $D_{v .5 e}$, respectively; i.e., $m_{d}=\rho_{\ell} \pi D_{v .5 e}^{3} / 6 . C_{d}$ is the drag coefficient based on characteristic length, $D_{v} .5 e$. 
Rewriting Eq. (2) in terms of $\Delta V_{d}^{2}$, over the distance $\Delta \mathrm{x}$, the following relationship is obtained:

$$
\frac{\Delta \mathrm{V}_{\mathrm{d}}^{2}}{\Delta \mathrm{x}}=\frac{3 \rho_{\mathrm{g}}\left(\mathrm{V}_{\mathrm{g}}-\mathrm{V}_{\mathrm{d}}\right)^{2}}{2 \rho_{\mathrm{l}} \mathrm{D}_{\mathrm{v} .5 \mathrm{e}}} \mathrm{C}_{\mathrm{d}}
$$

where $C_{d}=27 R^{0.84}$, as given in Ref. 2 , and $R e$ is based on characteristic dropsize, $D_{\mathrm{v} .5 e}$.

Deceleration of atomizing gases helium, nitrogen and argon into a low-velocity airflow was determined as follows. Gas velocity at the nozzle orifice was equal to the acoustic velocity, $\mathrm{V}_{\mathrm{c}}$. Values of $\mathrm{V}_{\mathrm{g}}$ used to solve Eq. (3) were calculated at downstream distances of $x$ $=5$ and $10 \mathrm{~cm}$, respectively, and plotted in Fig. 5 . Values of $\mathrm{V}_{\mathrm{g}}$ are based on data given in Ref. 12 and plotted in Fig. 5 for comparison. The percent deceleration of the atomizing gas was assumed to be approximately the same in both cases, since the two-fluid nozzles used in Ref. 12 and the one used in the present study are very similar in design.

To determine acceleration of $\mathrm{LN}_{2}$ droplets characterized by $D_{v .5 e}$, values of $V_{d}^{2}$ were calculated by numerically integrating Eq. (3) and plotting $V_{d}^{2}$ against downstream distance, $\mathrm{x}$, as shown in Fig. 6 . Vaporization time, $\mathrm{t}$, was calculated from this plot by means of the expression $\Delta t=x / V_{d}$. Calculated values of $\Delta \mathrm{t}$ for a given distance $\Delta \mathrm{x}$ are given in Table III, along with calculated Reynolds numbers averaged over the distance $\Delta \mathrm{x}$ and values of $\mathrm{D}_{\mathrm{v} .5 \mathrm{e}}$. Atomizing-gas transport properties used in calculating vaporization times are given in Table IV.

\section{Cryogenic Spray Vaporization Rate}

Spray vaporization rates, as based on characteristic dropsize, $D_{v .5 e}$, were calculated using the heat-balance expression: $\mathrm{dm}_{\mathrm{d}} / \mathrm{dt}=\mathrm{hA} \Delta \mathrm{T} / \mathrm{H}_{\mathrm{t}}$, where $\mathrm{h}$ is the heattransfer coefficient and $\mathrm{A}$ is spray surface-area based on $\mathrm{D}_{\mathrm{v} \cdot 5 \mathrm{e}} \cdot \Delta \mathrm{T}=\mathrm{T}_{\mathrm{g}}-\mathrm{T}_{\mathrm{d}}$ and $\mathrm{H}_{\mathrm{t}}=\mathrm{H}_{\mathrm{v}}+\mathrm{C}_{\mathrm{p}} \Delta \mathrm{T} . \mathrm{H}_{\mathrm{v}}$ is the latent heat of vaporization of $\mathrm{LN}_{2}$ and $\mathrm{C}_{\mathrm{p}}$ is the specific heat of nitrogen vapor. To determine vaporization rate in terms of droplet surface-area changes with time, the heat-balance was rewritten as follows:

$$
\frac{-\mathrm{D}_{\mathrm{v} .5}^{2}}{\Delta \mathrm{t}}=\frac{4 \mathrm{k}_{\mathrm{g}} \Delta \mathrm{T} \mathrm{Nu}}{\rho_{\ell} \mathrm{H}_{\mathrm{t}}}
$$

where $\mathrm{k}_{\mathrm{g}}$ and $\rho_{\ell}$ are gas thermal conductivity and liquid density, respectively. Previous fuel droplet studies reported in Ref. 2 used a high-speed droplet tracking camera to determine vaporization rates of jet-A fuel, n-octane, benzene, acetone, water and several other liquids. In that study, it was found that $\mathrm{Nu}=\mathbf{2}$ $+0.303 \operatorname{Re}^{0.6}$, where $\mathrm{Nu}$ is the Nusselt number and Re $=\rho_{\mathrm{g}} \mathrm{D}_{\mathrm{v} .5 \mathrm{e}} \Delta \mathrm{V} / \mu_{\mathrm{g}} \cdot \Delta \mathrm{V}$ is the velocity difference averaged over incremental distance $\Delta \mathrm{x}$. Vaporization rate calculations are based on characteristic diameter $D_{\mathrm{v} .5 \mathrm{e}}$. Atomizing-gas viscosity and thermal conductivity are evaluated at the average gas-film temperature, i.e., $\mathrm{T}_{\mathrm{f}}=$ $1 / 2\left(T_{g}-T_{\ell}\right) . L_{2}$ droplet surface temperatures were assumed to be close to the boiling point, $77 \mathrm{~K}$, as droplets were being accelerated and partially vaporized. Latent heat of vaporization of $\mathrm{LN}_{2}$ was evaluated at $77 \mathrm{~K}$ and the specific heat of nitrogen vapor was evaluated at the average gas-film temperature $T_{f}$

The initial unvaporized volume median diameter squared, $\mathrm{D}_{\mathrm{v} .5}^{2}$, was calculated from experimental measurements of $D_{\mathrm{v} .5 \mathrm{e}}^{2}$ and values of $-\Delta \mathrm{D}_{\mathrm{v} .5}^{2}$ obtained from Eq. (4), by means of the following expression:

$$
-\Delta \mathrm{D}_{\mathrm{v} .5}^{2}=\mathrm{D}_{\mathrm{v} .5 \mathrm{c}}^{2}-\mathrm{V}_{\mathrm{v} .5 \mathrm{e}}^{2}
$$

Calculated values of $\mathrm{D}_{\text {v.5c }}^{2}$ were correlated with atomizing-gas flowrate, $\mathrm{W}_{\mathrm{g}}$, as shown in Fig. 7 , and the following expression was obtained:

$$
\mathrm{D}_{\mathrm{v} .5 \mathrm{c}}^{-1}=264 \mathrm{~W}_{\mathrm{g}}^{1.33}
$$

when nitrogen gas was used to atomize the $\mathrm{LN}_{2}$ jets. Comparing Eq. (6) with Eq. (1), which gave $D_{v .5 e}^{-1}$ $=275 \mathrm{~W}_{\mathrm{g}}^{1.11}$ for nitrogen gasflow, shows that values of $\mathrm{k}_{\mathrm{e}}$ and $\mathrm{k}_{\mathrm{c}}$ are nearly the same. However, the value of exponent $\mathrm{n}$ for the partially vaporized sprays is considerably less, i.e., 1.11 as compared with 1.33 given in Eq. (6). This indicates a marked effect of droplet vaporization on dropsize measurements and also shows good agreement of calculated values of $\mathrm{n}$ with atomization theory ${ }^{13}$ which predicts $n=1.33$, for liquid jet breakup in high-velocity gasflow. The agreement of Eq. (6) with theory indicated the fact that a characteristic dropsize for the initial spray, $D_{v .5 c}$ can be computed by using heat-transfer and drag coefficient expressions reported in Ref. 2.

Correlation of $\mathrm{D}_{0} / \mathrm{D}_{\mathrm{v}} .5 \mathrm{c}$ With Dimensionless Force $\underline{\text { Ratios }}$

Values of $D_{v .5 c}$ were normalized with respect to $\mathrm{LN}_{2}$-jet diameter, $\mathrm{D}_{\mathrm{o}}$, and plotted against the product of We, Re and $\rho_{\mathrm{g}} / \rho_{\ell}$, i.e., the Weber number, Reynolds number and fluid-density ratio, respectively, as shown in Fig. 8. The following expression was derived:

$$
\frac{\mathrm{D}_{\mathrm{o}}}{\mathrm{D}_{\mathrm{v} .5 \mathrm{c}}}=\mathrm{k}_{\mathrm{c}}^{\prime}\left(\mathrm{WeRe} \frac{\rho_{\mathrm{g}}}{\rho_{\mathrm{l}}}\right)^{0.44}
$$


where WeRe is the ratio of aerodynamic to $\mathrm{LN}_{2}$-jet surface forces, i.e., liquid viscosity and surface tension. The fact that three plots are shown in Fig. 8 indicates that coefficient $k_{c}^{\prime}$ is also a function of some other physical properties of the three atomizing gases.

\section{Effect of Atomizing-Gas Properties on $\mathrm{LN}_{2}$-Jet Breakup}

In the present study of $\mathrm{LN}_{2}$-jet breakup in twofluid fuel nozzles, the main objective was to derive a single correlating expression for $\mathrm{D}_{\mathrm{o}} / \mathrm{D}_{\mathrm{v} .5 \mathrm{c}}$ that would be valid for a wide variety of atomizing gases. Figure 8 shows the product of the Weber and Reynolds numbers and the fluid-density ratio do not give a single correlating expression. Therefore, to accomplish this study's objective, the normalized volume median diameter ratio, $\mathrm{D}_{\mathrm{o}} / \mathrm{D}_{\mathrm{v} .5 \mathrm{c}}$, as produced by liquid jet atomization in twofluid fuel nozzles is also assumed to be a function of: the rms gas molecular velocity, $V_{m}$, liquid density, $\rho_{\ell}$, gas viscosity, $\mu_{g}$, and to be normalized with respect to acceleration of the gas molecules due to gravity, g. As a result, by means of dimensionless analysis, the following expressions were derived:

$$
\frac{\mathrm{d}_{\mathrm{o}}}{\mathrm{D}_{\mathrm{v} .5 \mathrm{c}}}=\mathrm{f}\left(\mathrm{V}_{\mathrm{m}}, \mu_{\mathrm{g}}, \rho_{\ell}, \mathrm{g}\right)
$$

where $V_{m}=\left(3 R T_{g} / M_{g}\right)^{0.5},{ }^{14} \mathrm{Eq}$. (8) may be rewritten as:

$$
\frac{\mathrm{D}_{\mathrm{o}}}{\mathrm{D}_{\mathrm{v} .5}}=\mathrm{f}\left(\rho_{\ell}\right)^{\mathrm{a}}\left(\mathrm{V}_{\mathrm{m}}\right)^{\mathrm{b}}(\mathrm{g})^{\mathrm{c}}\left(\mu_{\mathrm{g}}\right)^{\mathrm{d}}
$$

The preceding equation can be expressed in terms of the mass-length-time system (where $\mathrm{T}$ is time; $\mathrm{M}$, mass; and $\mathrm{L}$, length) to give:

$$
\frac{\mathrm{D}_{\mathrm{o}}}{\mathrm{D}_{\mathrm{v} .5}}=\left[\frac{\mathrm{M}}{\mathrm{L}^{3}}\right]^{\mathrm{a}}\left[\frac{\mathrm{L}}{\mathrm{T}}\right]^{\mathrm{b}}\left[\frac{\mathrm{L}}{\mathrm{T}^{2}}\right]^{\mathrm{c}}\left[\frac{\mathrm{M}}{\mathrm{LT}}\right]^{\mathrm{d}}
$$

As a result:

$$
\begin{gathered}
M ; 0=a+d \\
T ; 0=-b-2 c-d \\
L ; 0=-3 a+b+c-d
\end{gathered}
$$

which gives:

$$
\begin{gathered}
a=-d \\
b=-2 c-d=-3 d \\
c=3 a-b+d=d
\end{gathered}
$$

Substitution of these values into Eq. (9) gives:

$$
\frac{\mathrm{D}_{\mathrm{o}}}{\mathrm{D}_{\mathrm{v} .5}}=\mathrm{f}\left(\frac{\rho_{\mathrm{l}} \mathrm{V}_{\mathrm{m}}^{3}}{\mathrm{~g} \mu_{\mathrm{g}}}\right)^{-\mathrm{d}}
$$

In order to derive a correlating expression for $\mathrm{He}$, $\mathrm{N}_{2}$ and $\mathrm{Ar}$, as atomizing gases for two-fluid fuel nozzles, the correlation coefficient, $\mathbf{k}^{\prime}$ is plotted against $\rho_{\ell} \mathrm{V}_{\mathrm{m}}^{3} / \mathrm{g} \mu_{\mathrm{g}}$. From the slope of the plot shown in Fig. 3, the following relationship is obtained:

$$
\mathrm{k}_{\mathrm{c}}^{\prime \prime} \sim\left(\frac{\rho_{\ell} \mathrm{V}_{\mathrm{m}}^{3}}{\mathrm{~g} \mu_{\mathrm{g}}}\right)^{0.75}
$$

and the exponent $-\mathrm{d}$, derived from dimensionless analysis, is shown to equal 0.75 . Since this exponent is fairly large, the variables $\mu_{\mathrm{g}}, \rho_{\ell}$ and $\mathrm{V}_{\mathrm{m}}$ have considerable effect on the liquid-jet breakup process.

To obtain a single correlating coefficient for the three atomizing gases, values of $D_{o} / D_{v .5 c}$ are plotted against the dimensionless groups given in Eqs. (7) and (12), as shown in Fig. 10. Thus, the three atomizing gases gave the following expression:

$$
\frac{\mathrm{D}_{\mathrm{o}}}{\mathrm{D}_{\mathrm{v} .5 \mathrm{c}}}=5.70 \times 10^{-11}\left(\mathrm{WeRe} \frac{\rho_{\mathrm{g}}}{\rho_{\mathrm{l}}}\right)^{0.44}\left(\frac{\rho_{\mathrm{l}} \mathrm{V}_{\mathrm{m}}^{3}}{\mathrm{~g} \mu_{\mathrm{g}}}\right)^{0.75}
$$

In a previous study reported in Ref. 15, it was found that the effect of normalized atomizing-gas temperature $\mathrm{T}_{\mathrm{g}} / \mathrm{T}_{\mathrm{o}}$ on $\mathrm{D}_{\mathrm{v} \cdot 5 \mathrm{c}}^{-1}$ could be expressed as follows:

$$
\frac{\mathrm{D}_{\mathrm{o}}}{\mathrm{D}_{\mathrm{v} .5 \mathrm{c}}}=9\left(\mathrm{WeRe} \frac{\rho_{\mathrm{g}}}{\rho_{\ell}}\right)^{0.44}\left(\frac{\mathrm{T}_{\mathrm{g}}}{\mathrm{T}_{\mathrm{o}}}\right)^{1.25}
$$

which shows $D_{v}^{-1} \cdot 5 c \sim T_{g}^{1.25}$. Equation (13) indicates $\mathrm{D}_{\mathrm{v} .5 \mathrm{c}}^{-1} \sim\left(\rho_{\mathrm{\ell}} \mathrm{V}_{\mathrm{m}}^{3} / \mathrm{g} \mu_{\mathrm{g}}\right)^{0.75} \sim \mathrm{T}_{\mathrm{g}}^{0.53}$, since $\mu_{\mathrm{g}} \sim \mathrm{T}_{\mathrm{g}}^{0.8}$. Thus, $\left(\rho_{\ell} \mathrm{V}_{\mathrm{m}}^{3} / \mathrm{g} \mu_{\mathrm{g}}\right)^{0.75}\left(\mathrm{~T}_{\mathrm{g}} / \mathrm{T}_{\mathrm{o}}\right)^{0.72} \sim \mathrm{T}_{\mathrm{g}}^{1.25}$. Since the exponents 0.75 and 0.72 are practically the same, Eq. (13) may be rewritten as follows:

$$
\frac{\mathrm{D}_{\circ}}{\mathrm{D}_{\mathrm{v} .5 \mathrm{c}}}=5.7 \times 10^{-11}\left(\mathrm{WeRe} \frac{\rho_{\mathrm{g}}}{\rho_{\mathrm{l}}}\right)^{0.44}\left[\left(\frac{\rho_{\mathrm{l}} \mathrm{V}_{\mathrm{m}}^{3}}{\mathrm{~g} \mu_{\mathrm{g}}}\right)\left(\frac{\mathrm{T}_{\mathrm{g}}}{\mathrm{T}_{\mathrm{o}}}\right)\right]^{0.75}
$$


where the correlation, $5.7 \times 10^{-11}$ remains the same, since $T_{o}=T_{g}$ in the present study. Also, it was found that since $\operatorname{WeRe}\left(\rho_{\ell} / \rho_{\mathrm{g}}\right)=\mathrm{D}_{\mathrm{o}}^{2}\left(\rho_{\mathrm{g}} \mathrm{V}_{\mathrm{c}}\right)^{3} / \mu_{\ell} \rho_{\ell} \sigma ; \mathrm{D}_{\mathrm{v} .5 \mathrm{c}}^{-1}$ is proportional to $\mathrm{V}_{\mathrm{c}}^{1.33}, \mathrm{~V}_{\mathrm{m}}^{2.25}, \rho_{\ell}^{0.31}$ and gas molecular weight raised to the -0.46 power. For the liquid properties. $D_{v .5 c}^{-1}$ is proportional to $\mu_{\ell}^{-0.44}, \sigma^{-0.44}$ and $\rho_{\ell}^{0.31}$. The liquid-property exponents give relatively good agreement with those predicted in Ref. 13 from atomization theory for liquid-jet breakup in highvelocity gasflow.

\section{Concluding Remarks}

In working with cryogenic sprays such as $\mathrm{LN}_{2}$, it is difficult to obtain reproducible data on dropsize measurements, unless the liquid temperature is kept well below the boiling point and the hydrodynamic pressure drop across the fuel nozzle is low enough to prevent flash boiling during the formation of a cryogenic spray. A reproducibility of dropsize data of \pm 5 percent was obtained by adhering to the above mentioned requirements for studying $\mathrm{LN}_{2}$-jet breakup in sonic velocity gasflow.

\section{References}

1. Ingebo, R.D., "Experimental and Theoretical Effects of Nitrogen Gas Flowrate on Liquid Jet Atomization," Journal of Propulsion and Power, Vol. 4, No. 6, Nov.-Dec. 1988, pp. 406-411.

2. Ingebo, R.D., "Atomization, Acceleration and Vaporization of Liquid Fuels," Sixth Symposium (International) on Combustion, Reinhold Publishing Corporation, New York, 1957, pp. 684-687.

3. Kim, K.Y., and Marshall, W.R., Jr., "Drop Distributions from Pneumatic Atomizers," AIChE Journal, Vol. 17, No. 3, May 1971, pp. 575-584.

4. Lorenzetto, G.E., and Lefebvre; A.H., "Measurements of Drop Size on a Plain-Jet Airblast Atomizer," AIAA Journal, Vol. 15, No. 7, July 1977, pp. 1006-1010.

5. Nukiyama, S., and Tanasawa, Y., "Experiments on the Atomization of Liquids by Means of a Air Stream, Parts III-IV," Transactions of the Society of Mechanical Engineers, Japan, Vol. 5, No. 18, Feb. 1939, pp. 63-75.

6. Weiss, M.A., and Worsham, C.H., "Atomization in High Velocity Airstreams," American Rocket
Society Journal, Vol. 29, No. 4, Apr. 1959, pp. 252-259.

7. Wolf, H.E., and Andersen, W.H., "Aerodynamic Break-up of Liquid Drops," Proceedings of the 5th International Shock Tube Symposium, edited by Z.I. Slawasky, J.F. Moulton, Jr., and W.S. Filler, Naval Ordnance Lab., White Oak, MD, 1966, pp. 1145-1169. (Avail. NTIS, AD-638011.)

8. Buchele, D.R., "Particle Sizing by Weighted Measurements of Scattered Light," NASA TM-100968, 1988.

9. Swithenbank, J., Beer, J.M., Taylor, D.S., Abbot, D., and McCreath, G.C., "A Laser Diagnostic Technique for the Measurement of Droplet and Particle Size Distribution," Experimental Diagnostics in Gas Phase Combustion Systems, edited by B.T. Zinn and C.T. Bowman, Progress in Astronautics and Aeronautics, Vol. 53, AIAA, New York, 1977, pp. 421-447.

10. Felton, P.G., Hamidi, A.A., and Aigal, A.K., "Measurement of Drop-Size Distribution in Dense Sprays by Laser Diffraction," from No. 12: ICLASS-86; Proceedings of the Third International Conference on Liquid Atomization and Spray Systems, Vol. 2, edited by P. Eisenklam and A. Yule, Institute of Energy, London, UK, 1985, pp. IVA/4/1-IVA/4/11.

11. Ingebo, R.D., and Buchele, D.R., "Scattered-Light Scanner Measurements of Cryogenic Liquid-Jet Breakup," NASA TM-102432, 1990.

12. Bulzan, D.L., Levy, Y., Aggarwal, S.K., and Chitre, S., "Measurements and Predictions of a Liquid Spray From an Air-Assist Nozzle," Atomization and Sprays, vol. 2, 1992, pp. 445-462.

13. Adelberg, M., "Mean Drop Size Resulting From The Injection of a Liquid Jet Into a High Speed Gas Stream," AIAA Journal, Vol. 6, No. 6, June 1986, pp. 1143-1147.

14. Glasstone, S., Textbook of Physical Chemistry, D. Van Nostrand Co., Inc., New York, 2nd Edition, 1946, p. 253.

15. Ingebo, R.D., "Atomizing-Gas Temperature Effects on Cryogenic Spray Dropsize, NASA TM-106106, 1993. 
TABLE I.-ATOMIZING-GAS VELOCITY EXPO-

NENT， n, LIQUID-JET BREAKUP IN

HIGH-VELOCITY GASFLOW

\begin{tabular}{|c|c|}
\hline Source & $\begin{array}{c}\text { Exponent, } \\
-\mathbf{n}\end{array}$ \\
\hline Adelberg, Theory ${ }^{13}$ & 1.33 \\
\hline Present study, $x=2.2 \mathrm{~cm}$ & 1.33 \\
\hline Kim and Marshall ${ }^{3}$ & 1.14 \\
\hline Lorenzetto and Lefebvre ${ }^{4}$ & 1.00 \\
\hline Nukiyama and Tanasawa, ${ }^{5} x=5$ to $25 \mathrm{~cm}$ & 1.00 \\
\hline Weiss and Worsham ${ }^{6}$ & 1.33 \\
\hline Wolf and Anderson ${ }^{7}$ & 1.33 \\
\hline
\end{tabular}

TABLE II.-EQUATIONS (1) AND (2)

COEFFICIENTS AND EXPONENTS

\begin{tabular}{|l|r|r|r|c|}
\hline \multirow{2}{*}{$\begin{array}{c}\text { Atomizing } \\
\text { gas }\end{array}$} & \multicolumn{2}{|c|}{$\begin{array}{c}\text { Partially } \\
\text { vaporized } \\
\mathrm{LN}_{2} \text { spray, } \\
\text { experimental }\end{array}$} & \multicolumn{2}{c|}{$\begin{array}{c}\text { Original } \\
\text { unvaporized } \\
\mathrm{LN}_{2} \text { spray, } \\
\text { calculated }\end{array}$} \\
\cline { 2 - 5 } & $\mathrm{k}_{\mathrm{e}}$ & $\mathrm{n}_{\mathrm{e}}$ & $\mathrm{k}_{\mathrm{c}}$ & $\mathrm{n}_{\mathrm{c}}$ \\
\hline Helium & 1125 & 1.16 & 1911 & 1.33 \\
Nitrogen & 275 & 1.11 & 263 & 1.33 \\
Argon & 222 & 1.08 & 162 & 1.33 \\
\hline
\end{tabular}

$$
\begin{aligned}
& { }^{a} D_{\mathrm{v} \cdot 5 \mathrm{e}}^{-1}=\mathrm{k}_{\mathrm{e}} \mathrm{W}_{\mathrm{g}}^{\mathrm{n}} \\
& { }^{\mathrm{b}} \mathrm{D}_{\mathrm{v} \cdot 5 \mathrm{c}}^{-1}=\mathrm{k}_{\mathrm{c}} \mathrm{W}_{\mathrm{g}}^{\mathrm{n}} .
\end{aligned}
$$

TABLE III.-VAPORIZATION TIME, $\triangle \mathrm{t}$, AND

REYNOLDS NUMBER FOR $\mathrm{D}_{\mathrm{v} \cdot 5 \mathrm{e}}^{-1}$

\begin{tabular}{|l|c|c|c|c|}
\hline $\begin{array}{c}\text { Atomizing } \\
\text { gas }\end{array}$ & $\begin{array}{c}\mathrm{W}_{\mathrm{g}}, \\
\mathrm{g} / \mathrm{sec}\end{array}$ & $\begin{array}{c}\mathrm{D}_{\mathrm{v}}^{-1} \cdot \mathrm{fm}^{\mathrm{e}} \\
\mathrm{cm}\end{array}$ & $\begin{array}{c}\Delta \mathrm{t} \times 10^{4}, \\
\mathrm{sec}\end{array}$ & $\mathrm{Re}$ \\
\hline Helium & 1.00 & 1125 & 1.35 & 15.2 \\
Nitrogen & 4.54 & 1650 & 1.44 & 35.3 \\
Argon & 5.43 & 1370 & 1.52 & 31.4 \\
\hline
\end{tabular}

TABLE IV.-ATOMIZING-GAS TRANSPORT PROPERTIES, AT $\mathrm{T}_{\mathrm{f}}=188 \mathrm{~K}$ AND

\begin{tabular}{|l|c|c|c|}
\hline \multicolumn{1}{|c}{$\mathrm{W}_{\mathrm{g}}=4.54 \mathrm{~g} / \mathrm{sec}$} \\
\begin{tabular}{|l|l|} 
Atomizing \\
gas
\end{tabular} & $\begin{array}{c}\mathrm{V}_{\mathrm{c}} \times 10^{-4}, \\
\mathrm{~cm} / \mathrm{sec}\end{array}$ & $\begin{array}{c}\mu_{\mathrm{f}} \times 10^{4}, \\
\mathrm{~g} / \mathrm{cm} \mathrm{sec}\end{array}$ & $\begin{array}{c}\mathrm{k}_{\mathrm{f}} \times 10^{5}, \\
\mathrm{cal} / \mathrm{sec} \mathrm{sq} \mathrm{cm}, \\
{ }^{\circ} \mathrm{C} / \mathrm{cm}\end{array}$ \\
\hline Helium & 9.10 & 1.98 & 26.3 \\
Nitrogen & 3.43 & 1.25 & 4.2 \\
Argon & 2.87 & 1.10 & 2.85 \\
\hline
\end{tabular}




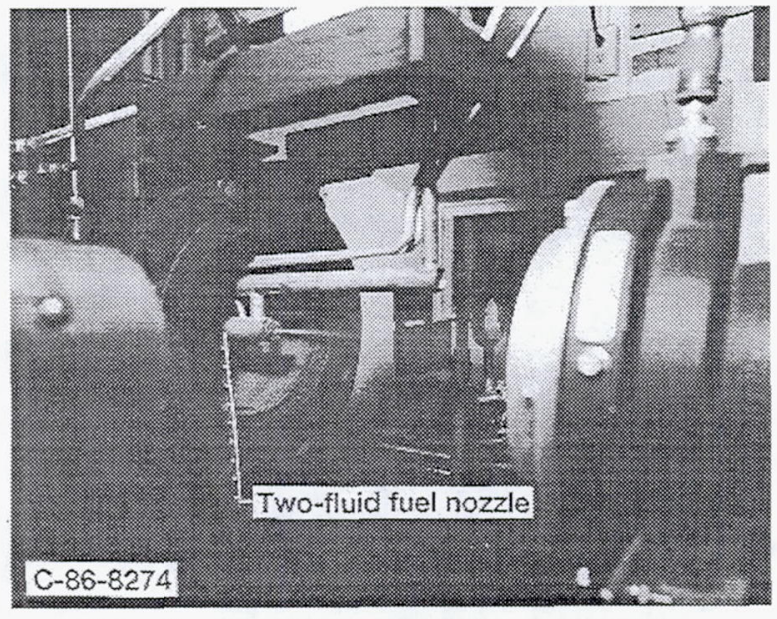

Figure 1.-Apparatus and auxiliary equipment.

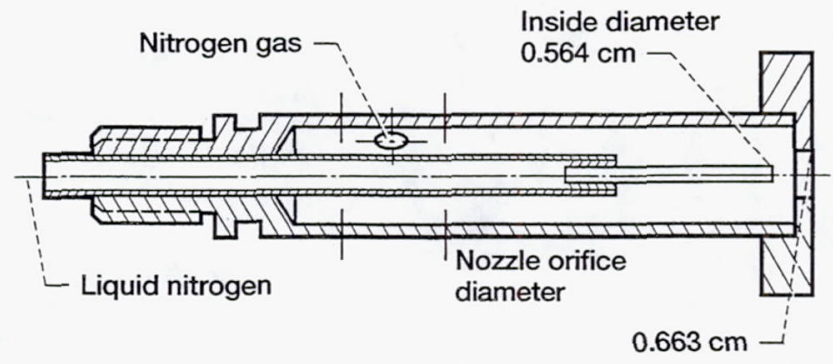

Figure 2.-Diagram of pneumatic two-fluid atomizer.

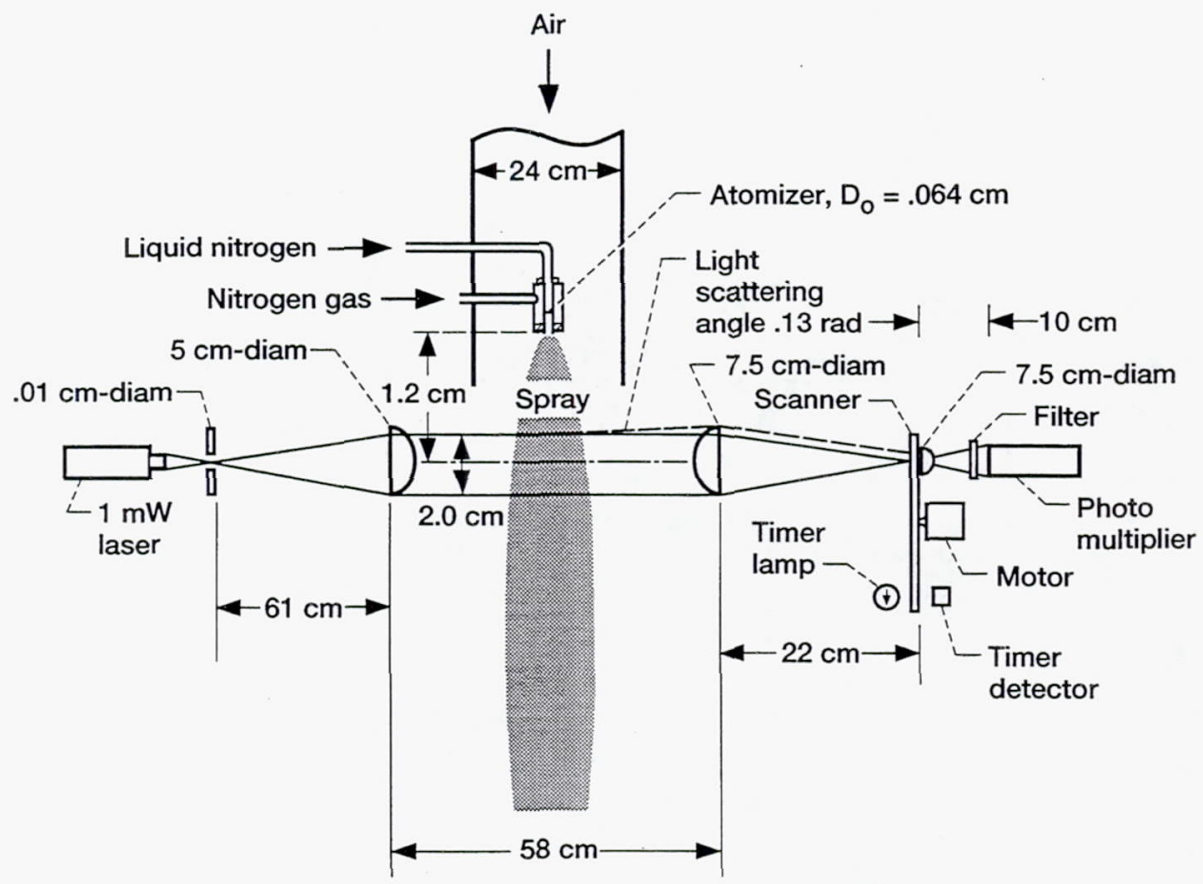

Figure 3.-Atmospheric pressure test section and optical path of scattered-light scanner. 


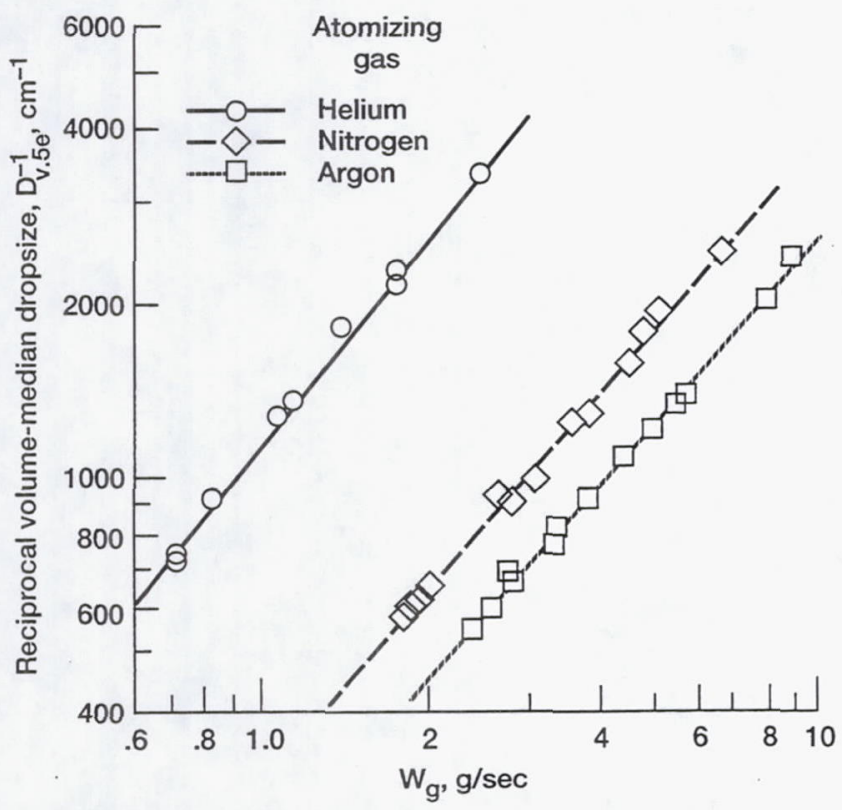

Figure 4.-Effect of atomizing-gas flowrate on experimentally determined reciprocal volume-median dropsize, $D_{v .5 e}$.

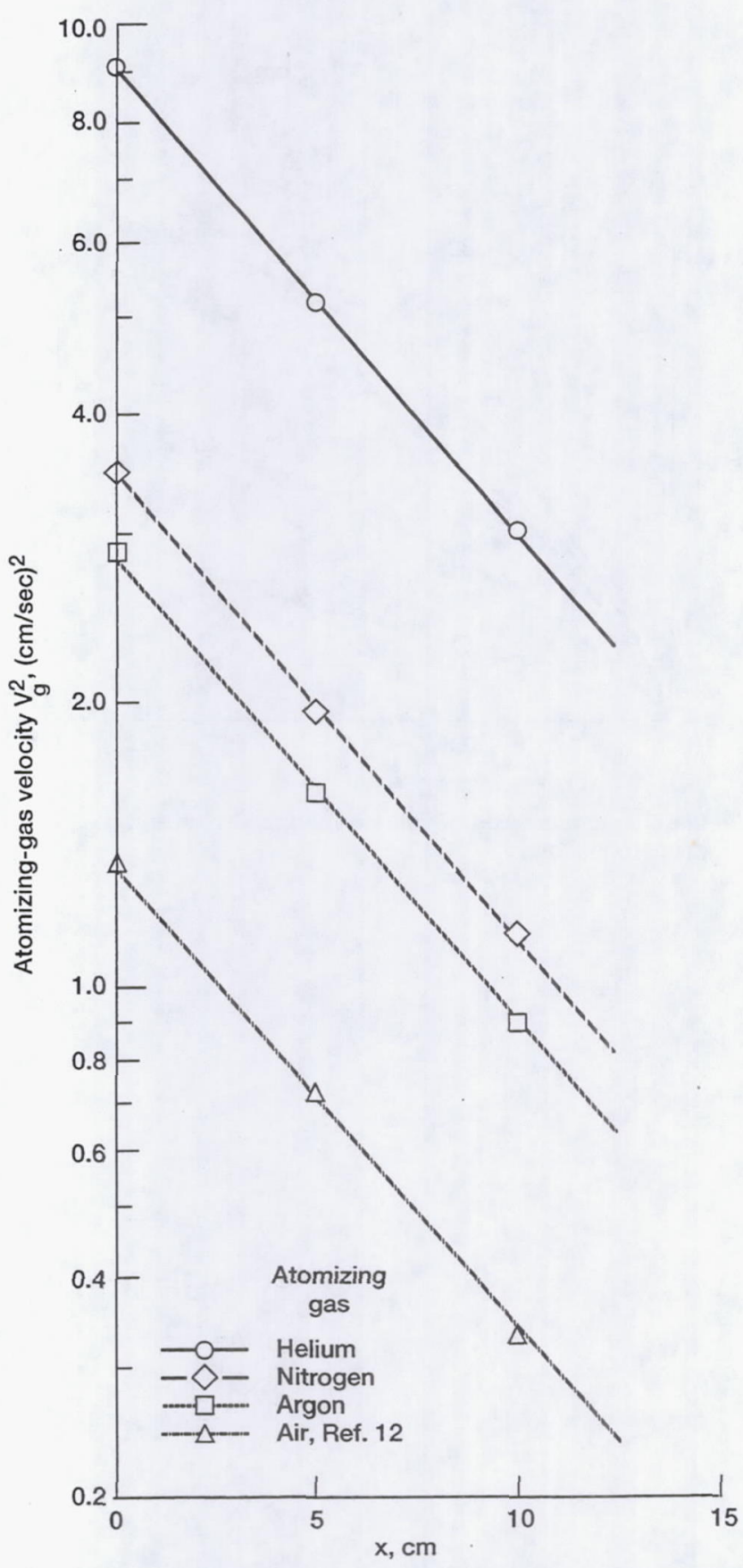

Figure 5.-Deceleration of atomizing-gases downstream of fuel-nozzle orifice. At $\mathrm{x}=0, \mathrm{v}_{\mathrm{g}}=\mathrm{V}_{\mathrm{c}}$. 


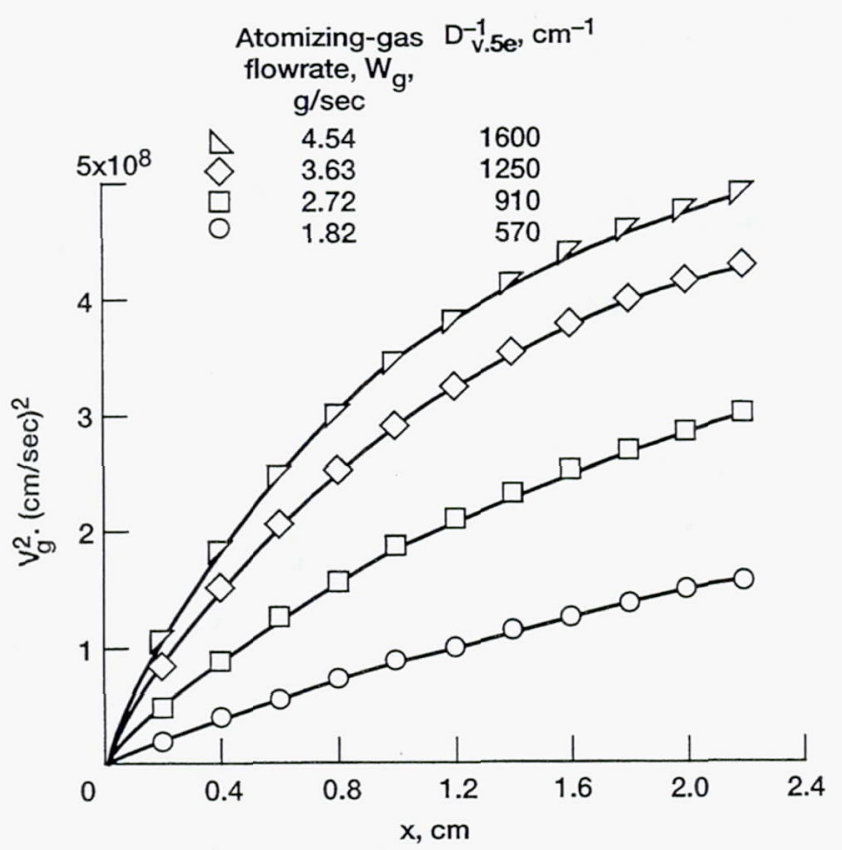

Figure 6.-Acceleration of volume-median dropsize, $D_{v .5 e}$, in nitrogen gasflow.

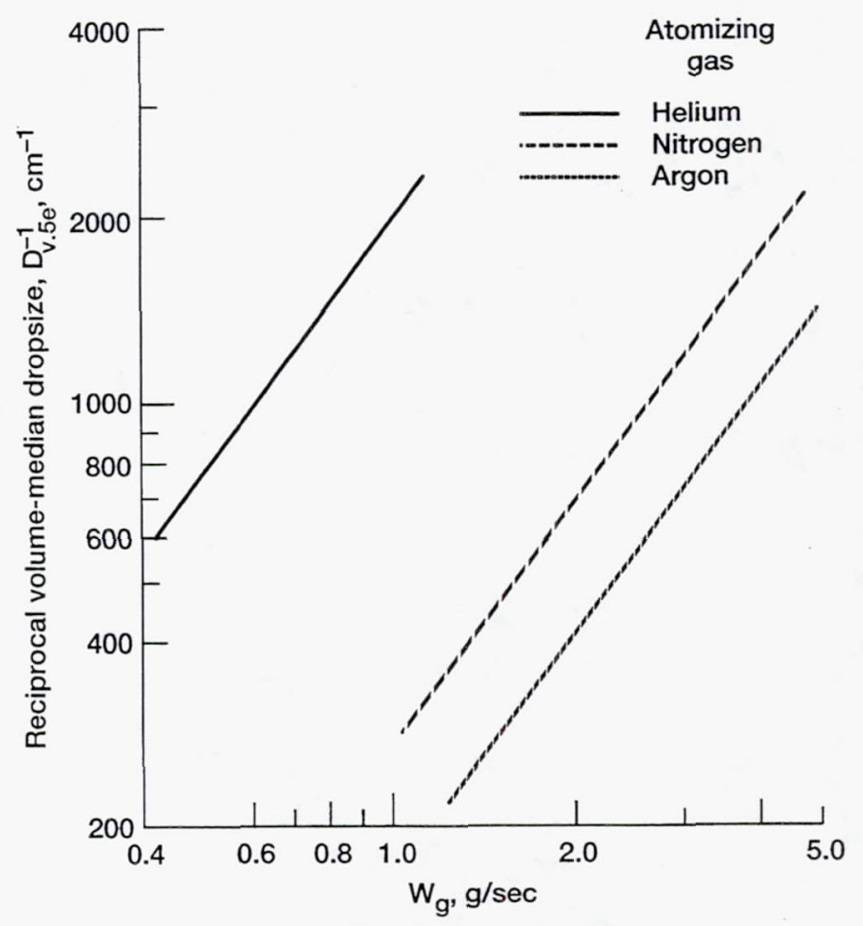

Figure 7.-Effect of $W_{g}$ on initially unvaporized $D_{v .5 e}$, at fuelnozzle orifice, $x=0$.

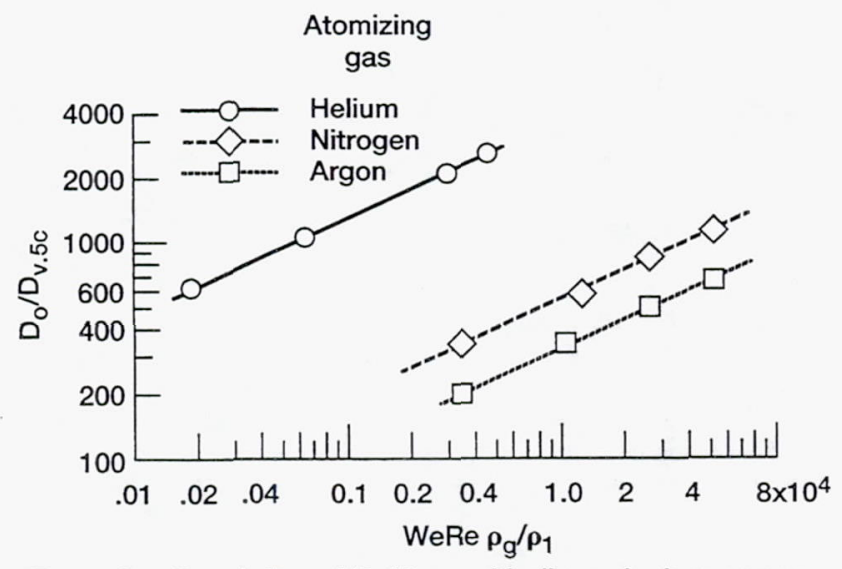

Figure 8.-Correlation of $D_{0} / D_{v .5 c}$ with dimensionless groups. 


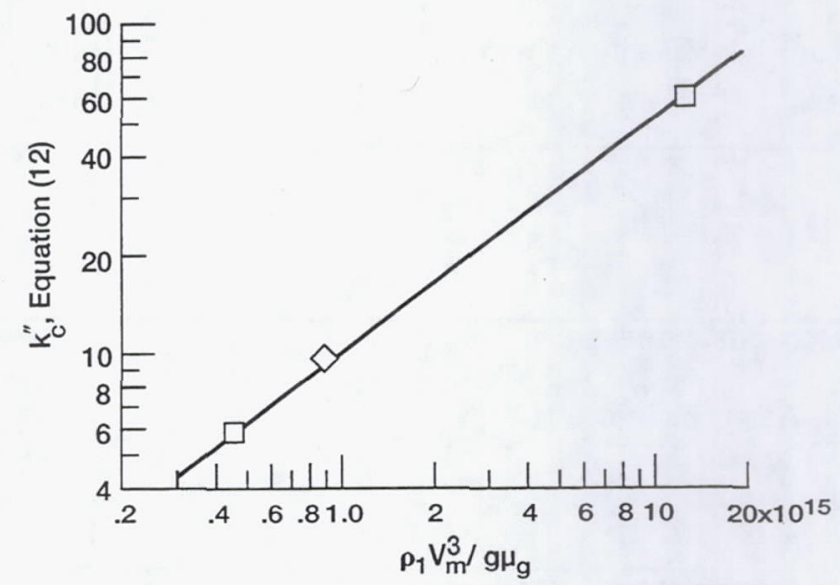

Figure 9.-Correlation of coefficient $k^{1}$ with dimensionless group, $\rho_{1} \mathrm{~V}_{\mathrm{m}}^{3} / \mathrm{g} \mu_{\mathrm{g}}$.

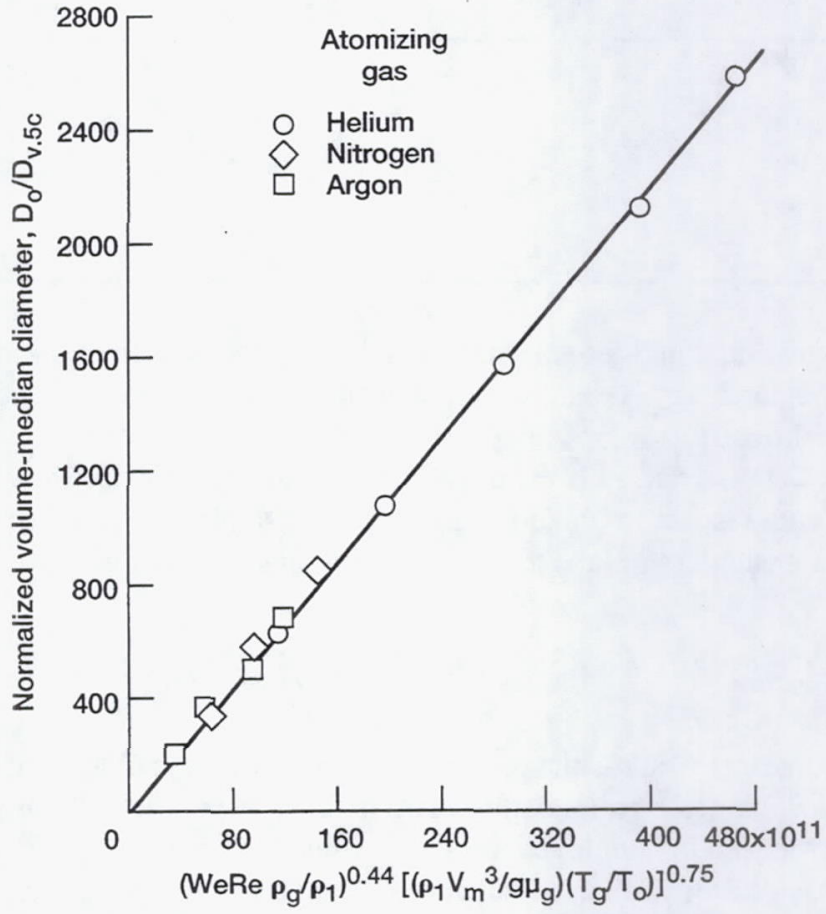

Figure 10.-Correlation of volume-median diameter, $D_{v .5 c}$, with dimensionless groups. 
Public reporting burden for this collection of information is estimated to average 1 hour per response, including the time for reviewing instructions, searching existing data sources, gathering and maintaining the data needed, and completing and reviewing the collection of information. Send comments regarding this burden estimate or any other aspect of this collection of information, including suggestions for reducing this burden, to Washington Headquarters Services, Directorate for Information Operations and Reports, 1215 Jefferson Davis Highway, Suite 1204, Arlington, VA 22202-4302, and to the Office of Management and Budget, Paperwork Reduction Project (0704-0188), Washington, DC 20503.

\begin{tabular}{|l|c|c|}
\hline 1. AGENCY USE ONLY (Leave blank) & $\begin{array}{c}\text { 2. REPORT DATE } \\
\text { October } 1993\end{array}$ & $\begin{array}{r}\text { 3. REPORT TYPE AND DATES COVERED } \\
\text { Technical Memorandum }\end{array}$ \\
\hline
\end{tabular}

4. TITLE AND SUBTITLE

Cryogenic Spray Vaporization in High-Velocity Helium, Argon and Nitrogren Gasflows

\section{AUTHOR(S)}

Robert D. Ingebo
5. FUNDING NUMBERS

WU-505-62-52

\section{PERFORMING ORGANIZATION NAME(S) AND ADDRESS(ES)}

National Aeronautics and Space Administration

Lewis Research Center

Cleveland, Ohio 44135-3191
8. PERFORMING ORGANIZATION REPORT NUMBER

E-8161
9. SPONSORING/MONITORING AGENCY NAME(S) AND ADDRESS(ES)

National Aeronautics and Space Administration

Washington, D.C. 20546-0001
10. SPONSORING/MONITORING AGENCY REPORT NUMBER

NASA TM-106363

AIAA-94-0687

11. SUPPLEMENTARY NOTES

Prepared for the AIAA 32nd Aerospace Sciences Meeting and Exhibit sponsored by the American Institute of Aeronautics and Astronautics, Reno, Nevada, January 10-13, 1994. Responsible person, Robert D. Ingebo, (216) 433-3586.

12a. DISTRIBUTION/AVAILABILITY STATEMENT

12b. DISTRIBUTION CODE

Unclassified - Unlimited

Subject Category 35

13. ABSTRACT (Maximum 200 words)

Effects of gas properties on cryogenic liquid-jet atomization in high-velocity helium, nitrogen and argon gasflows were investigated. Volume median diameter, $\mathrm{D}_{\mathrm{v}} .5 \mathrm{e}$, data were obtained with a scattered-light scanning instrument. By calculating the change in spray dropsize, $-\Delta \mathrm{D}_{\mathrm{v} .5}^{2}$, due to droplet vaporization, it was possible to calculate $\mathrm{D}_{\mathrm{v} .5 \mathrm{c}}$ from the expression, $-\Delta D_{v .5}^{2}=D_{v .5}^{2}-D_{v .5 c}^{2} . D_{v .5 c}$ is the unvaporized characteristic dropsize formed at the fuel-nozzle orifice. $D_{v .5 c}$ was normalized with respect to liquid-jet diameter, $D_{0}$, to give the dimensionless ratio $D_{0} / D_{v .5 c}$. It was then correlated with several dimensionless groups to give the following expression:

$$
\mathrm{D}_{\mathrm{o}} / \mathrm{D}_{\mathrm{v} .5 \mathrm{c}}=\mathrm{k}_{\mathrm{c}}\left(\mathrm{We} \operatorname{Re} \rho_{\mathrm{g}} / \rho_{\ell}\right)^{0.44}\left[\left(\rho_{\ell} \mathrm{V}_{\mathrm{m}}{ }^{3} / \mathrm{g} \mu_{\mathrm{g}}\right)\left(\mathrm{T}_{\mathrm{g}} / \mathrm{T}_{\mathrm{o}}\right)\right]^{0.75}
$$

where $\mathrm{k}_{\mathrm{c}}$ is a proportionality constant, WeRe is the product of Weber and Reynolds number, $\rho_{\mathrm{g}} / \rho_{\ell}$ is the fluid density ratio, and $\rho_{\ell} V_{m}^{3} / g \mu_{g}$ is a molecular-scale group derived in this study to correlate the original characteristic dropsize, $\mathrm{D}_{\mathrm{v} .5 \mathrm{c}}$, with atomizing forces produced by the three atomizing gases. This expression, for the volume median diameter of cryogenic $\mathrm{LN}_{2}$ sprays, correlates dropsize $\mathrm{D}_{\mathrm{v} .5 \mathrm{c}}$ with aerodynamic and liquid-surface forces so that it can be readily determined in the design of multiphase-flow propellant injectors for rocket combustors.

\section{SUBJECT TERMS}

Atomization; Vaporization; Fuel sprays; Dropsize; Cryogenic liquids; Heat-transfer; Drag coefficients

17. SECURITY CLASSIFICATION OF REPORT

Unclassified

18. SECURITY CLASSIFICATION
OF THIS PAGE
Unclassified

Unclassified
19. SECURTYY CLASSIFICATION OF ABSTRACT Unclassified 